\title{
Pulse wave velocity 24-hour monitoring with one-site measurements by oscillometry
}

\author{
This article was published in the following Dove Press journal: \\ Medical Devices: Evidence and Research \\ 18 February 2013 \\ Number of times this article has been viewed
}

\author{
Igor N Posokhov \\ Hemodynamic Laboratory Ltd, \\ Nizhniy Novgorod, Russia
}

Correspondence: Igor N Posokhov 69 Hemodynamic Laboratory 603009, Nizhniy Novgorod, Russia $\mathrm{Tel}+79159396222$

$\mathrm{Fax}+79138259111$

Email posokhov@24h-monitoring.com

\begin{abstract}
This review describes issues for the estimation of pulse wave velocity (PWV) under ambulatory conditions using oscillometric systems. The difference between the principles of measuring the PWV by the standard method and by oscillometry is shown, and information on device validation studies is summarized. It was concluded that currently oscillometry is a method that is very convenient to use in the 24-hour monitoring of the PWV, is relatively accurate, and is reasonably comfortable for the patient. Several indices with the same principles as those in the analysis of blood pressure in ambulatory monitoring of blood pressure, namely the assessment of load, variability, and circadian rhythm, are proposed.
\end{abstract}

Keywords: pulse wave velocity, 24-hour monitoring, oscillometry

\section{Introduction}

The indirect estimation of arterial stiffness by pulse wave velocity (PWV) measurement is very important in clinical practice. Epidemiologic evidences show that stiffening of elastic arteries formerly thought to be part of aging, precede, and independently predict clinical arterial hypertension, atherosclerosis, stroke, and myocardial infarction risks. ${ }^{1,2}$ It is well known that the stiffer the aorta is, the higher PWV is. Increased PWV is a diagnostic element for classifying subjects in the high or very high risk categories, as suggested by the Task Force for the Management of Arterial Hypertension of the European Society of Hypertension and of the European Society of Cardiology in the 2007 Guidelines. ${ }^{3}$ Thus, the PWV measurement is necessary to assess cardiovascular risk.

Pulse wave registration at two sites is traditionally used to obtain the distance (in meters) and the time interval (in seconds) needed for the PWV (in meters per second) equation. The reference standard for true PWV is simultaneous pressure waveforms recorded invasively from just above the aortic valve and just above the aortic bifurcation; the non-invasive reference is waveforms recorded by carotid and femoral artery tonometry. ${ }^{4}$

Carotid-femoral PWV is the closest to the true PWV and is used in clinical practice. However, emerging issues for the estimation of the PWV under ambulatory conditions should be noted. It is appropriate to parallel the potential usefulness of PWV ambulatory monitoring with the ambulatory monitoring of blood pressure (ABPM) in Europe: the diagnosis of hypertension has traditionally been based on measurements of blood pressure in the clinic, and recently, after evidence of reducing misdiagnosis reported in a cost-effectiveness study, ABPM was recommended for most patients. 5,6 
Notably, oscillometric systems for PWV monitoring are usually integrated into ABPM systems.

\section{Time interval measurement}

There is a difference between the principles of measuring the PWV by the standard method and by oscillometry. The main principle of the second method is to record the oscillations detected on the upper-arm cuff during systole and to separate the so-called forward and backward waves, described by Harvey in 1649. ${ }^{2}$ The blood volume ejected into the aorta generates the "early systolic peak," and then the pulse wave runs down and, after reflection, creates the second wave, known as the "late systolic peak." The return time (reflected wave transit time [RWTT]) is calculated as the difference in seconds between the initial and reflected systolic waves.

As shown in Figure 1, approaches to measuring the time interval can be different. Thus, the difference in the time between the pressure peaks or between the beginnings of the forward wave and of the reflected wave can be investigated. ${ }^{7,8}$

The travel and reflection of the arterial wave are very complex phenomena that cannot be described by simple conceptual models. ${ }^{9}$ However, today we have observed the progressive development of mathematical algorithms and computer technologies that analyze the oscillometric curve. ${ }^{10-12}$ For obvious reasons, manufacturers do not disclose the technical details of the wave separation and timing. However, theoretical aspects are widely presented in the available literature. ${ }^{13-16}$

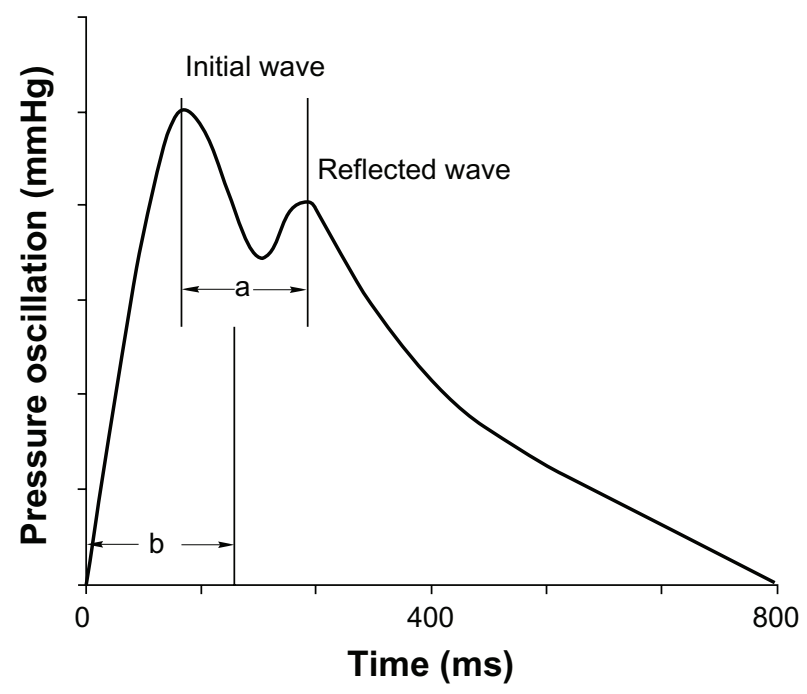

Figure I Methods of measuring the oscillometrically generated pulse wave. Notes: $\mathrm{a}=$ difference in the time between the pressure peak of the first wave and the reflected wave; $b=$ difference in the time between the beginnings of each wave.

\section{Distance measurement}

Measuring the distance in the present method is also different from the other PWV measuring methods. This distance can rightly be called "device-specific." 17

The recommended technique is based on measuring the distance from the sternal notch (jugulum) to the upper edge of the pubic bone (symphysis), two characteristic anatomical points (Figure 2).

Information that the jugulum-symphisis distance provides the nearest value of the true aortic length can be found in the descriptions of the method..$^{18}$ However, overall, this information refers to Sugawara et al, who computed the arterial lengths using three-dimensional transverse magnetic resonance image arterial tracings of the aorta and the carotid and iliac arteries in 256 apparently healthy adults ranging in age from 19 to 79 years and who also estimated the "effective reflection site" and "effective reflection distance." 19,20

It should also be noted that the findings of Sugawara et al were among the arguments in the recent publications on the distance for the carotid-femoral PWV. ${ }^{21-25}$ Based on these publications, the "Expert consensus document on the measurement of aortic stiffness in daily practice using carotid-femoral pulse wave velocity" was published in $2012 .{ }^{26}$ This document, which standardizes the PWV measurement, advises the use of $80 \%$ of the direct

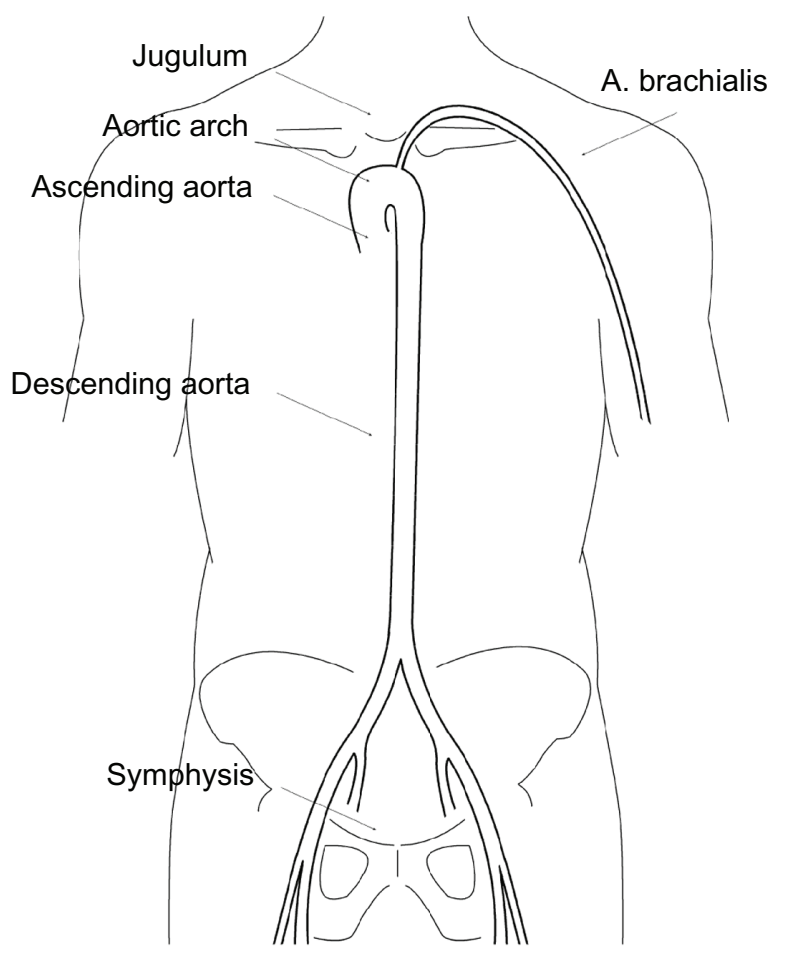

Figure 2 The jugulum-symphisis distance for the superficial morphologic measurement and projection of the aorta and arteria brachialis. 
carotid-femoral tape measure distance as the new standard and accordingly also advises the adaption of the cut-off value for the PWV of $10 \mathrm{~m} / \mathrm{second}$. The PWV cut-off value for oscillometric devices with one-site measurements is also $10 \mathrm{~m} /$ second exactly.

\section{Device studies}

Information on different device studies is summarized in Table 1.

Magometschnigg et al showed a low correlation between the compared methods, which was explained by the authors through the difference in the physical characteristics of the different arteries. ${ }^{7}$

Several following publications presented comparisons between oscillometric and more evaluated devices. Comparisons similar to validations were performed in accordance with ARTERY guidelines. ${ }^{4}$ Rajzer et al showed a higher PWV by Complior than by SphygmoCor and the oscillometric device Arteriograph. ${ }^{17}$ Baulmann et $\mathrm{al}^{8}$ and Jatoi et $\mathrm{al}^{27}$ described similar correlations between the PWVs of the SphygmoCor, Complior and Arteriograph, and noted the differences in the algorithms used to measure the travelled distance. Horváth et al evaluated the PWV of the oscillometric method versus invasive measurements obtained during cardiac catheterization procedures and reported an acceptable agreement between these measurements. ${ }^{18}$

Other articles are devoted to investigation of the reliability and the feasibility of oscillometric pulse wave velocity measurements. Ageenkova and Purygina in their test-retest reliability study of RWTT and other parameters measured by the BPLab-Vasotens device described good intraobserver and day-to-day repeatability and short-term reproducibility. They concluded that 24-hour monitoring of hemodynamic variables using the Vasotens technology can be recommended for vascular risk estimation in clinical practice. ${ }^{10}$ In the most recent paper, Luzardo et al assessed the feasibility of ambulatory pulse wave analysis by comparing this approach with an established tonometric technique and concluded that brachial oscillometry slightly underestimated the PWV under ambulatory conditions but is still feasible. ${ }^{28}$

\section{Conclusion}

It is necessary, in fairness, to mention the articles that questioned the principle of one-site PWV measurements by oscillometry. ${ }^{29-32}$ Further investigations may still be needed, including studies aimed at providing an invasive validation of the working principle of these devices. ${ }^{33}$ However, it can be noted that issues of the practical application of these methods will gradually come to the foreground. At present, oscillometry is a method that is very convenient for use in the 24-hour monitoring of PWV, is relatively accurate, and is reasonably comfortable for the patient. The most recent studies recommend it for ambulatory monitoring and indicate the feasibility of ambulatory PWV assessment. ${ }^{10,28}$

Finally, returning to the parallels with ABPM, several new indices may be proposed. These indices can have the same principles as those in the analysis of blood pressure in ABPM, namely the assessment of load, variability, and circadian rhythm. For example, it is clear that there are

Table I Studies of devices used for oscillometric pulse wave velocity measurements

\begin{tabular}{|c|c|c|c|c|}
\hline Study & $\begin{array}{l}\text { Number of } \\
\text { observations }\end{array}$ & Device & Method & Result \\
\hline Magometschnigg ${ }^{7}$ & 100 & TensioClinic & $\begin{array}{l}\text { Comparison with brachial PWV } \\
\text { (ShygmoCor) }\end{array}$ & $\begin{array}{l}\mathrm{m}: 9 . \mathrm{I} ; \mathrm{SD}: 1.8 \mathrm{~m} / \mathrm{second} \mathrm{vs} \\
\mathrm{m}: 8.4 ; \mathrm{SD}: 1.5 \mathrm{~m} / \mathrm{second} \\
\mathrm{r}=-0.04\end{array}$ \\
\hline Rajzer et al ${ }^{17}$ & 64 & Arteriograph & $\begin{array}{l}\text { Comparison with ShygmoCor } \\
\text { and with Complior }\end{array}$ & $\begin{array}{l}r=0.29(P=0.043) \text { and } r=0.36 \\
(P=0.0048)\end{array}$ \\
\hline Baulmann et $\mathrm{al}^{8}$ & 51 & Arteriograph & $\begin{array}{l}\text { Comparison with ShygmoCor } \\
\text { and with Complior }\end{array}$ & $\begin{array}{l}r=0.67(P<0.00 \mathrm{I}) \text { and } \mathrm{r}=0.69 \\
(P<0.00 \mathrm{I})\end{array}$ \\
\hline Jatoi et $\mathrm{al}^{27}$ & 254 & Arteriograph & Comparison with Complior & $r=0.60(P<0.00 I)$ \\
\hline Horváth et al ${ }^{18}$ & 22 & Arteriograph & $\begin{array}{l}\text { Comparison with invasively } \\
\text { measured PWV }\end{array}$ & Pearson's $r=0.91(P<0.00 \mathrm{I})$ \\
\hline Ageenkova and Purygina ${ }^{10}$ & 90 & BPLab & $\begin{array}{l}\text { Reproducibility and repeatability } \\
\text { study }\end{array}$ & $\begin{array}{l}\text { Reproducibility and repeatability: } \\
\text { good }\end{array}$ \\
\hline Luzardo et $\mathrm{al}^{28}$ & 35 & Mobil-O-graph & $\begin{array}{l}\text { Comparison with ShygmoCor } \\
\text { at rest }\end{array}$ & $\mathrm{m}: 7.3$ vs $\mathrm{m}: 7.0 \mathrm{~m} / \mathrm{second}$ \\
\hline Luzardo et $\mathrm{al}^{28}$ & 83 & Mobil-O-graph & $\begin{array}{l}\text { Comparison with ShygmoCor } \\
\text { (ambulatory) }\end{array}$ & $\mathrm{m}: 7.9$ vs $\mathrm{m}: 7.4 \mathrm{~m} / \mathrm{second}$ \\
\hline
\end{tabular}

Abbreviations: $m$, mean; PWV, pulse wave velocity; $r$, correlation coefficient; SD, standard deviation. 
differences in the clinical condition of patients who develop excess measurements of the PWV over the cut-off value for 0 or 50 or 100 percent of the monitoring period. Accordingly, the "time index" for PWV would be quite appropriate. It should be noted that in this case the quality of the test is determined not by accuracy and agreement with a reference method of PWV measurement but mostly by the cut-off point sensitivity and specificity.

\section{Disclosure}

The author reports no conflicts of interest in this work.

\section{References}

1. Vaitkevicius PV, Fleg JL, Engel JH, et al. Effects of age and aerobic capacity on arterial stiffness in healthy adults. Circulation. 1993;88(4 Pt 1):1456-1462.

2. Safar ME, O'Rourke MF, editors. Arterial Stiffness in Hypertension. Amsterdam: Elsevier; 2006.

3. Mancia G, De Backer G, Dominiczak A, et al. 2007 Guidelines for the management of arterial hypertension: The Task Force for the Management of Arterial Hypertension of the European Society of Hypertension (ESH) and of the European Society of Cardiology (ESC). J Hypertens. 2007;25(6):1105-1187.

4. Wilkinson IB, McEniery CM, Schillaci G, et al. ARTERY Society guidelines for validation of non-invasive haemodynamic measurement devices: Part 1, arterial pulse wave velocity. Artery Res. 2010;4(2): $34-40$.

5. Lovibond $\mathrm{K}$, Jowett $\mathrm{S}$, Barton $\mathrm{P}$, et al. Cost-effectiveness of options for the diagnosis of high blood pressure in primary care: a modelling study. Lancet. 2011;378(9798):1219-1230.

6. Hypertension [webpage on the Internet]. Hypertension: the clinical management of primary hypertension in adults: update of clinical guidelines 18 and 34. London: National Institute for Health and Clinical Excellence; 2011. Available from: http://www.nice.org. uk/guidance/CG127. Accessed January 23, 2013.

7. Magometschnigg D. Blood pressure and arterial stiffness. A comparison of two devices for measuring augmentation index and pulse wave velocity. Wien Med Wochenschr. 2005;155(17-18):404-410. German.

8. Baulmann J, Schillings U, Rickert S, et al. A new oscillometric method for assessment of arterial stiffness: comparison with tonometric and piezo-electronic methods. J Hypertens. 2008;26(3):523-528.

9. Segers P, Mynard J, Taelman L, Vermeersch S, Swillens A. Wave reflection: myth or reality? Artery Res. 2012;6(1):7-11.

10. Ageenkova OA, Purygina MA. Central aortic blood pressure, augmentation index, and reflected wave transit time: reproducibility and repeatability of data obtained by oscillometry. Vasc Health Risk Manag. 2011;7:649-656.

11. Wassertheurer S, Kropf J, Weber T, et al. A new oscillometric method for pulse wave analysis: comparison with a common tonometric method. J Hum Hypertens. 2010;24(8):498-504.

12. Rogoza AN, Kuznetsov AA. Central aortic blood pressure and augmentation index: comparison between Vasotens ${ }^{\circledR}$ and SphygmoCor ${ }^{\circledR}$ technology. Research Reports in Clinical Cardiology. 2012;3:27-33.

13. Chiu YC, Arand PW, Shroff SG, Feldman T, Carroll JD. Determination of pulse wave velocities with computerized algorithms. Am Heart J. 1991;121(5):1460-1470.

14. Westerhof BE, Guelen I, Westerhof N, Karemaker JM, Avolio A. Quantification of wave reflection in the human aorta from pressure alone: a proof of principle. Hypertension. 2006;48(4):595-601.
15. Westerhof $\mathrm{N}$, Westerhof $\mathrm{BE}$. Wave transmission and reflection of waves. "The myth is in their use". Artery Res. 2012;6(1):1-6.

16. Liao D, Arnett DK, Tyroler HA, et al. Arterial stiffness and the development of hypertension. The ARIC study. Hypertension. 1999; 34(2):201-206.

17. Rajzer MW, Wojciechowska W, Klocek M, Palka I, BrzozowskaKiszka M, Kawecka-Jaszcz K. Comparison of aortic pulse wave velocity measured by three techniques: Complior, SphygmoCor and Arteriograph. J Hypertens. 2008;26(10):2001-2007.

18. Horváth IG, Németh A, Lenkey Z, et al. Invasive validation of a new oscillometric device (Arteriograph) for measuring augmentation index, central blood pressure and aortic pulse wave velocity. $J$ Hypertens. 2010;28(10):2068-2075.

19. Sugawara J, Hayashi K, Yokoi T, Tanaka H. Age-associated elongation of the ascending aorta in adults. JACC Cardiovasc Imaging. 2008;1(6):739-748.

20. Sugawara J, Hayashi K, Tanaka H. Distal Shift of Arterial Pressure Wave Reflection Sites with Aging. Hypertension. 2010;56(5):920-925.

21. Sugawara J, Hayashi K, Yokoi T, Tanaka H. Carotid-femoral pulse wave velocity: impact of different arterial path length measurements. Artery Res. 2010;4(1):27-31.

22. O'Rourke M, Farnsworth A, O'Rourke J. Aortic dimensions and stiffness in normal adults. JACC Cardiovasc Imaging. 2008;1(6):749-751.

23. Vlachopoulos C, Aznaouridis K, Stefanadis C. Prediction of cardiovascular events and all-cause mortality with arterial stiffness: a systematic review and meta-analysis. JAm Coll Cardiol. 2010;55(13): 1318-1327.

24. Reference Values for Arterial Stiffness' Collaboration. Determinants of pulse wave velocity in healthy people and in the presence of cardiovascular risk factors: 'establishing normal and reference values'. Eur Heart J. 2010;31(19):2338-2350.

25. Salvi P, Magnani E, Valbusa F, et al. Comparative study of methodologies for pulse wave velocity estimation. J Hum Hypertens. 2008;22(10):669-677.

26. Van Bortel LM, Laurent S, Boutouyrie P, et al. Expert consensus document on the measurement of aortic stiffness in daily practice using carotidfemoral pulse wave velocity. J Hypertens. 2012;30(3):445-448.

27. Jatoi NA, Mahmud A, Bennett K, Feely J. Assessment of arterial stiffness in hypertension: comparison of oscillometric (Arteriograph), piezoelectronic (Complior) and tonometric (SphygmoCor) techniques. J Hypertens. 2009;27(11):2186-2191.

28. Luzardo L, Lujambio I, Sottolano M, et al. 24-h ambulatory recording of aortic pulse wave velocity and central systolic augmentation: a feasibility study. Hypertens Res. 2012;35(10):980-987.

29. Trachet B, Reymond P, Kips J, et al. Numerical validation of a new method to assess aortic pulse wave velocity from a single recording of a brachial artery waveform with an occluding cuff. Ann Biomed Eng. 2010;38(3):876-888

30. Segers P, Kips J, Trachet B, et al. Limitations and pitfalls of noninvasive measurement of arterial pressure wave reflections and pulse wave velocity. Artery Res. 2009;3(2):79-88.

31. Boutouyrie P, Revera M, Parati G. Obtaining arterial stiffness indices from simple arm cuff measurements: the holy grail? J Hypertension. 2009;27(11):2159-2161.

32. Westerhof BE, van den Wijngaard JP, Murgo JP, Westerhof N. Location of a reflection site is elusive: consequences for the calculation of aortic pulse wave velocity. Hypertension. 2008;52(3):478-483.

33. Parati G, De Buyzere M. Evaluating aortic stiffness through an arm cuff oscillometric device: is validation against invasive measurements enough? J Hypertens. 2010;28(10):2003-2006. 
Medical Devices: Evidence and Research

Dovepress

\section{Publish your work in this journal}

Medical Devices: Evidence and Research is an international, peerreviewed, open access journal that focuses on the evidence, technology, research, and expert opinion supporting the use and application of medical devices in the diagnosis, treatment and management of clinical conditions and physiological processes. The identification of novel devices and optimal use of existing devices which will lead to improved clinical outcomes and more effective patient management and safety is a key feature. The manuscript management system is completely online and includes a quick and fair peer-review system. Visit http://www. dovepress.com/testimonials.php to read real quotes from authors.

Submit your manuscript here: http://www.dovepress.com/medical-devices-evidence-and-research-journal 